\title{
UMA VISÃO DA CRÍTICA DA ARTE BRASILEIRA NO SÉCULO XIX: ANGELO AGOSTINI
}

Rosangela de Jesus Silva ${ }^{1}$

\section{Resumo}

A crítica realizada por Angelo Agostini através das caricaturas e dos textos nos mostram uma grande inquietação do artista para com as Belas Artes.

Nessa comunicação gostaríamos de enfocar um pouco da visão de Agostini com relação à crítica de arte. Sua opinião foi bastante severa. Para Agostini a crítica não era construtiva. Ou era feita para enobrecer os artistas incondicionalmente, ou ao contrário feita de forma a destruir as possibilidades em torno do artista, ou seja, uma crítica sem medidas ou limites de bom senso. Mesmo com todas essas reservas, Agostini acreditava na importância da crítica, pois através dela se julgavam os trabalhos e desta forma poderia se contribuir muito para o desenvolvimento dos artistas, para seu aperfeiçoamento. A crítica era considerada um instrumento de distinção fundamental para a arte.

Palavras-chave: crítica de arte; Angelo Agostini; Brasil século XIX

A crítica de arte produzida na segunda metade do século XIX no Brasil teve como seu palco a imprensa da época. Nomes como Baudelaire, Sthendal, Guizot, Quatremère de Quincy, Valenciennes, Delecluze, Zola, Gustave Planche, Thoré, Charles Blanc, Théophile Gauthier, entre muitos outros nos remetem imediatamente para as discussões do século XIX em torno do Neoclassicismo, do Romantismo, do Realismo, do Idealismo, enfim das idéias estéticas que permearam a produção artística naquele período. Idéias que em grande medida influenciaram a crítica no Brasil, já que a França e tudo o que ela representava foi muito importante no âmbito cultural brasileiro. Contudo pensar o caso brasileiro nos apresenta algumas particularidades indispensáveis à compreensão desse fenômeno.

Um ponto muito importante a ser considerado é a ausência de grandes autoridades e de um veículo de divulgação específico para a crítica. Embora já com Manuel de Araújo Porto Alegre $^{2}$, na primeira metade do século XIX, a preocupação com a questão artística tivesse tomado uma proporção maior. Porto Alegre foi crítico, buscou reformular o ensino da Academia através da Reforma Pedreira, bem como pensava numa produção artística de caráter brasileiro. Também exerceu importante papel no IHGB - Instituto Histórico e Geográfico Brasileiro, criado em 1838, o qual foi uma iniciativa de reflexão da questão nacional em seus aspectos mais amplos, com grande interesse, segundo Mário Barata ${ }^{3}$, no nosso passado e presente artístico.

Porém, só teremos um periódico dedicado às belas artes em 1879, que foi a Revista Musical e de Belas Artes (1879-1880), a qual como já diz o título também tratava da questão musical considerada a frente das artes em termos de desenvolvimento e novidades. Esse

\footnotetext{
${ }^{1}$ Doutoranda em História da Arte - Departamento de História, IFCH - UNICAMP (Universidade Estadual de Campinas), e-mail: rosangelad@gmail.com

2 Para maiores referências sobre Araújo Porto Alegre ver: SQUEFF, Letícia. O Brasil nas letras de um pintor: Manuel de Araújo Porto Alegre.Campinas, SP: Editora da UNICAMP, 2004.

3 BARATA, Mário. As artes plásticas de 1808 a 1889. In: HOLLANDA, Sergio Buarque. O Brasil Monárquico. 3 vol. Reações e transações. São Paulo: Difusão Européia do livro, 1967. p.409-443.
} 
periódico teve curta duração, dois anos, porém, acreditamos que tenha sido um importante meio de divulgação dos debates artísticos.

Em seu primeiro ano, no número 15 a revista expressa a seguinte opinião sobre a crítica no Brasil:

\footnotetext{
Ninguém mais do que nós conhece o quanto são incompetentes os críticos de música e bellas-artes no nosso paiz; mas também o que conhecemos é que, bons ou mãos, estão a altura das obras que tem de criticar.

No Brazil, é certo, não há um Ruskin, um Planche, um Viardot, um Theophilo Gautier; mas também não é menos certo que não temos um Turner, um Delacroix, um Ingres, um Messonier.

Portanto: bons ou mãos, os nossos críticos, para o que têm de criticar - chegam!4
}

Somente na década de oitenta teremos publicado um livro dedicado a fazer crítica no Brasil que é o livro de Felix Ferreira Belas artes: Estudos e apreciações, publicado em 1885. Seu intuito é a análise da produção artística daquele momento. Ferreira apresenta a seguinte opinião sobre as exposições:

(...) as exposições concorrem para apurar o bom gosto público, e enquanto este não estiver na altura das sociedades cultas, a arte não passará entre nós de passatempo. ${ }^{5}$

Depois desse livro, em 1888, Gonzaga Duque Estrada publica $A$ arte Brasileira. Livro até hoje referência para o estudo da arte no século XIX brasileiro. Segundo Chiarelli em sua introdução de A Arte Brasileira, Duque Estrada procurou pensar a arte produzida no Brasil além do ambiente carioca buscando uma dimensão maior da cultura nacional.

(...) O autor desejava refletir sobre em que medida a produção visual aqui levada a cabo corresponderia às necessidades intrínsecas da nação brasileira, da cultura aqui produzida. ${ }^{6}$

O pensamento de Duque Estrada, fortemente influenciado por H. Taine, via no estudo a grande redenção do artista.

Em um país colocado nas atuais circunstancias em que se acha o Brasil, só estudos longos e muita meditação podem elevar o artista à sua merecida posição e dar-lhe os elementos para a sua independência de pensar e agir. $(. . .)^{7}$

Dentre esses personagens que se preocuparam com o fenômeno artístico no Brasil encontramos Angelo Agostini, conhecido por suas caricaturas permeadas de humor e ironia e seu forte posicionamento contra a escravidão, a monarquia e a Academia de Belas Artes.

O grande veículo de comunicação utilizado por Agostini foi a Revista Illustrada (18761898), no qual esteve a frente desde sua fundação até 1888. Na Revista Ilustrada a preocupação com as belas artes, teve bastante espaço, talvez porque a revista tenha tido uma duração mais longa, ou porque era de Agostini e este sendo artista pode dar mais espaço para este tema. De qualquer forma não podemos deixar de notar que as questões artísticas, principalmente depois

\footnotetext{
${ }^{4}$ Os textos da época aqui reproduzidos não sofreram nenhuma correção, portanto respeitam a grafia original.

${ }^{5}$ FERREIRA, Felix. Belas artes: Estudos e apreciações. Texto extraído de Publicações digitais Artedata.

${ }^{6}$ CHIARELLI, Domingos Tadeu. Introdução. In: DUQUE ESTRADA, Gonzaga Duque. A Arte Brasileira. Campinas - SP: Mercado das Letras, 1995. p.21

${ }^{7}$ DUQUE ESTRADA, Gonzaga Duque. A Arte Brasileira. Campinas - SP: Mercado das Letras, 1995. p 262.
} 
de 1879 tomaram uma dimensão muito maior no cenário da corte, portanto um personagem como Ângelo Agostini, não poderia ter se mantido alheio àquele debate.

A crítica realizada por Angelo Agostini, além daquela direcionada à Academia, tocaria também na questão da crítica de arte daquele momento, assim como á produção e aos artistas. Suas opiniões apresentadas variavam de certo humor, permeado às vezes por acidez e muita liberdade para mencionar artistas e trabalhos que lhe agradavam ou não, além de grande ironia.

Com relação à crítica brasileira sua opinião foi bastante severa. Para Agostini a crítica não era construtiva. Ou era feita para enobrecer os artistas incondicionalmente, ou ao contrário feita de forma a destruir as possibilidades em torno do artista, ou seja, uma crítica sem medidas ou limites de bom senso.

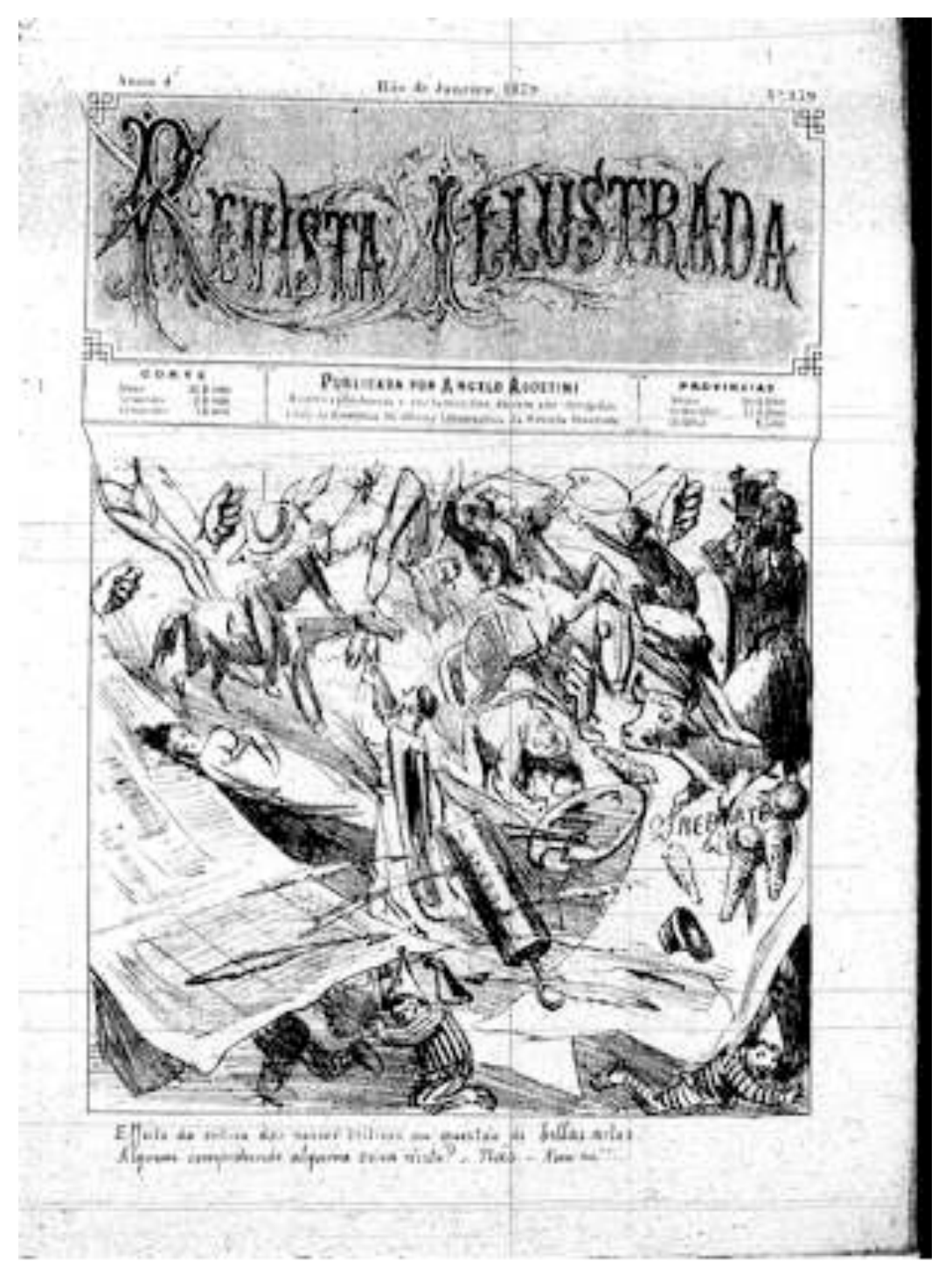

A ilustração acima, que não parece muito clara, não está assim apenas por um problema de reprodução, é realmente um desenho confuso e pelo comentário que segue abaixo fica 
bastante claro o intuito da ilustração. Agostini reproduz o alvoroço, ebulição e confusão que via suscitar na crítica brasileira, expressa no número 159 da Revista Illustrada em 1879.

Com algum esforço é possível identificar na ilustração páginas de periódicos, veículos nos quais a crítica era divulgada, sendo atingidos por penas com pontas agudas atiradas em várias direções. Também observamos que há pessoas que se escondem atrás das páginas. Há paletas e pincéis atirados. No canto esquerdo, ao lado da folha de jornal aparece uma figura que se assemelha a uma escultura caída e com expressão triste. Também é possível observar na cena animais como cavalos e um boi, assim como pessoas observando atônitas, como as do canto superior direito, e mais à frente personagens que parecem brigar. É realmente um quadro caótico o apresentado.

Essa caricatura é de 1879, como já foi dito, um momento muito importante no panorama artístico brasileiro, no qual foi acesa uma grande polêmica em torno das Batalhas de Avaí e Guararapes, respectivamente de Pedro Américo e Victor Meireles. ${ }^{8} \mathrm{O}$ debate tomou a imprensa carioca com discussões acerca de possíveis plágios que os artistas em questão teriam cometido, com relação à verdade histórica ou não, com relação ao movimento ou ausência dele nas personagens retratados, bem como uma discussão, que tomará mais corpo depois, que foi aquela em torno do caráter nacional da produção artística.

Agostini estava fortemente inserido nesses debates, portanto nesta caricatura, daria o seu parecer acerca do acirramento daquelas discussões, também ilustrado no texto publicado em 8 de maio de 1879 na revista que diz o seguinte:

E discute-se com paixão, encarniçadamente na imprensa, nos theatros, nos cafés, nas palestras familiares, até na própria Academia se discute bellas-artes!

Os debates floresciam na imprensa à medida que uma nova exposição acontecia, assim, depois da grande polêmica de 79, surge um intervalo, no qual pouco se fala de belas artes. Só em 1882 foram retomadas as discussões novamente com maior força quando da exposição realizada no Liceu de Artes e Ofícios. E com a crítica acontece o mesmo, portanto nesse ano Agostini fez o seguinte comentário:

Não distinguir o bom do soffrivel ou do medíocre, não pôde agradar senão aos que se acham n'esta ultima classificação. Mas o que se há de fazer?... Não se pôde exigir que a nossa imprensa tenha críticos da força de Charles Blanc, Theophilo Gauthier e outros. E se por acaso os tivesse, estou bem certo que quase todos os artistas se empenhariam para que não fallassem das suas obras. ${ }^{?}$

Neste trecho fica evidente o quanto Agostini acreditava na importância da crítica, pois através dela se julgavam os trabalhos e desta forma poderia se contribuir muito para o desenvolvimento dos artistas, para seu aperfeiçoamento. A crítica era considerada um instrumento de distinção fundamental para a arte.Todavia, Agostini sabia da dificuldade em fazer crítica de arte. Acreditava que o público poderia não entender a crítica e assim prejudicar o artista. Em seus escritos percebe-se algum descrédito com relação à compreensão da arte por parte do público o que tornaria esse público passível de ser enganado.

8 Ver: GUARILHA, Hugo. A questão artística de 1879: um episódio da crítica de arte no II Reinado. Anais do XXIII Colóquio do Comitê Brasileiro de História da Arte. Rio de Janeiro: 2004.p. 195-202. O trabalho está sendo desenvolvido em uma tese de mestrado desenvolvida no departamento de História do IFCH na UNICAMP.

${ }^{9}$ Revista Illustrada, Rio de Janeiro, 1882, ano VII, n.292. p.3 


\begin{abstract}
Nada conheço mais difficil do que dar uma opinião franca sobre qualquer obra d'arte. Dizer o que se pensa, o que se sabe, o que se vê; notar esta ou aquella incorrecção, descuido ou defeito: louvar o que é bom e apontar o que não é, são cousas que não se podem fazer entre nós.

E porque? Porque infelizmente nunca ou quasi nunca se fazem criticas sensatas e conscienciosas; porque poucos entendem e muitos escrevem sem nada entender. Não posso explicar d'outro modo certos louvores immerecidos que leio às vezes nos jornaes, acerca de verdadeiros disparates expostos em algumas casas da rua do Ouvidor, e uma completa indifferença quando se trata de trabalhos que tem algum mérito.

Ora, como em geral o nosso publico não tem a menor intuição do que é arte, facilmente deixa se illudir pelo que lê nos jornaes, onde elle suppõe haver pessoas habilitadas para emittirem uma opinião. ${ }^{10}$
\end{abstract}

Nas críticas de Agostini também é possível observar a questão política em seus comentários. Quando neste trecho acima o autor se refere a trabalhos ruins expostos na rua do Ouvidor é um claro posicionamento. A rua do ouvidor era um local freqüentado pela corte carioca, com suas confeitarias, lojas da moda, ali se concentravam monarquistas e simpatizantes, portanto, nada mais natural do que um republicano, crítico do império desacreditar tudo o que estivesse naquele ambiente e por conseqüência as obras ali expostas, pois certamente eram admiradas pela elite imperial.

Agostini acreditava que devido a tantos problemas de várias ordens que o país enfrentava era realmente difícil que a crítica de arte tivesse um grande espaço.

Mesmo em paizes adiantadíssimos os críticos de arte são raros. Entre nós, porém, é quase tentar o impossível, pois em uma sociedade torturada como a nossa, por problemas cruéis, a attenção pública não está ainda desassombrada para cuidar d'esses assumptos. E a crítica é destinada a corresponder ou a elucidar uma preocupação geral, por este ou aquelle assumpto. ${ }^{11}$

Talvez seja curioso observar a reação de Agostini ao primeiro livro dedicado a crítica e as Belas Artes no Brasil. Estudos e Apreciações sobre Belas Artes de Felix Ferreira, quando foi anunciada sua publicação, o empreendimento foi bastante elogiado, porém, quando lido, nosso crítico não gostou nem um pouco do que viu:

Depois de folhear este volume do Sr. Felix Ferreira, passamos a fazer uma leitura mais demorada, e, posto que nos inspire sempre consideração qualquer tentativa ou trabalho, e que pesássemos bem a magnitude do assumpto, as decepções foram grandes!

(...)

Para muitos artistas de mérito, que o Sr.Felix Ferreira não comprehendeu, a sua crítica será um motivo de não pequeno desgosto. (...)

Por outro lado, o insenso é queimado ás mãos cheias, sobre trabalhos de um mérito todo de convenção, obras primas officiaes, decretadas não se sabe por quem!

Resumindo: o Sr. Felix Ferreira deve empregar o seu brilhante talento de escriptor em outra qualquer especialidade.

Não trate mais de bellas artes.

Tenha pena d'ellas! ${ }^{12}$

\footnotetext{
${ }^{10}$ Revista Illustrada, Rio de Janeiro, 1884, ano IX, n.374. p.6

11 Revista Illustrada, Rio de Janeiro, 1885, ano X, n.407. p.7

12 Revista Illustrada, Rio de Janeiro, 1885, ano X, n.408. p.7
} 
Para Agostini, Felix Ferreira fez apenas repetir o discurso institucional em seu livro, louvando os artistas reconhecidos pelo meio oficial. Dessa forma não teria contribuído verdadeiramente para o desenvolvimento artístico no país, além é claro de estar ao lado do poder instituído, o que para o crítico já tiraria qualquer mérito do seu trabalho.

Chama-se atenção do público para que este fique atento ao que se diz dos artistas e das obras, tornando-se assim preparado para não se deixar enganar pela crítica.

O que devemos fazer é não sermos tão Beocios: não dar ouvidos a elogios partidos de bocca propria, nem a parvoíces encomiásticas que se escrevem a propósito de grandes quadros, sem se indagar se estes são produtos originaes do talento do artista, ou se não passam de manta de retalhos, habilidosamente aliavadas, e com os quaes o autor, pretendendo tapar a vista dos que a tem perspicaz, embrulha, de facto, os pascacios boquiabertos, que iludidos, começam a dar bordoadas de cego no bom senso, incensando, á direita e á esquerda, o nome do próprio mágico, que lhes virou o juízo. ${ }^{13}$

Um outro momento bastante indicativo da opinião de Agostini foi sua polêmica com Gonzaga Duque Estrada em torno da exposição das obras de Henrique Bernadelli, organizada por seu irmão o escultor Rodolpho Bernardelli em 1886 no Rio de Janeiro. Inicialmente o descontentamento de agostini se dá contra a crítica no geral que não teria reconhecido o talento de Henrique e por isso sua exposição não teria alcançado o sucesso merecido. Agostini afirmava que a crítica brasileira não saberia reconhecer um grande artista. A crítica teria dito que Henrique seria uma esperança e nesse termo começa a discordância de Agostini. Como Henrique o qual cuidava de sua formação na Itália há sete anos, portanto com uma boa produção já realizada, poderia apenas representar uma esperança? Já seria um artista consolidado. Assim, quando o artigo assinado por Alfredo Palheta, pseudônimo de Duque Estrada n'A Semana, contesta o trabalho de Henrique Bernardelli de forma a criticar questões técnicas da pintura, Agostini através de X, seu pseudônimo, desfere duras palavras:

Mas não podíamos deixar passar tantos disparates e tanto pedantismo da parte de um individuo que tem a petulância de querer passar por entendido aos olhos do público, quando na realidade, elle não passa de um... tolo, muito ignorante. ${ }^{14}$

Agostini contesta nos escritos de A. Palheta as questões técnicas apontadas, rebatendo cada observação. Como Agostini era artista certamente se julgava mais capacitado para fazer referências desse tipo, ao passo que Duque Estrada não teria formação artística suficiente e, portanto, não seria habilitado para fazer tais reflexões. Para ilustrar reproduziremos abaixo um trecho da crítica, sendo a primeira frase de A. Palheta e o comentário de Agostini.

Noto, também, abuso de tons azues e de sombras violáceas, já nas figuras já nas paizagens.

(...) Se o Ilustre crítico se desse o trabalho de reflectir, veria que as paisagens e figuras feitas em pleno ar, não podem deixar de participar da luz do céo: sendo este azul, toda a parte que não for iluminada pelo sol há de ser forçosamente azulada, sobretudo nos planos mais distantes. ${ }^{15}$

\footnotetext{
${ }^{13}$ Revista Illustrada, Rio de Janeiro, 1885, ano X, n.419. p.3

${ }^{14}$ Revista Illustrada, Rio de Janeiro, 1886, ano XI, n.444. p.3 e 6

15 ibid, p.3 e 6.
} 
Os comentários de Agostini para com a crítica não sedem espaço, continuam duros. Sua visão é sempre muito negativa, acreditava-se que a crítica realizada era danosa. Esse era certamente mais um aspecto da sociedade com o qual não concordava, e que queria mudar e reformular.

Quando digo que os artistas não devem ficar aqui, é unicamente por causa dos nossos críticos em bellas artes, que, não entendendo absolutamente nada desta matéria, concorrem poderosamente para arruinar qualquer vocação artística com elogios bombasticos e estapafurdios, a propósito de qualquer borracheira pintada.

O resultado d'isto é que quase todos os que foram enthusiasticamente elogiados pela nossa imprensa, tem ido para traz ou ficaram completamente estacionários por julgarem ter attingido ao nec plus ultra da perfeição. ${ }^{16}$

Para o crítico, embora fosse difícil e desagradável expressar opiniões negativas, elas por vezes eram necessárias e deveriam ser feitas, pois a crítica deveria ser honesta, imparcial e consciente de que a arte brasileira ainda teria um longo caminho a seguir.

Sempre é desagradavel falar mal de alguma cousa, mas é que acima das considerações pessoaes, ha o dever a esse impõe-nos a obrigação de proseguir no caminho da critica, mas da critica justa, imparcial e honesta. O nosso fim é melhorar o que deve ser melhorado.

Somos brandos ás vezes e implacaveis em outras. Em questão de bellas-artes temos sido indulgentes em geral com todos, pois comprehendendo que a arte entre nós ainda está na infancia, não podemos ter exigencias que seriam mal cabidas e até tolas; medimos então a nossa critica pela bitola do adiantamento relativo em que se acha o nosso paiz em materia de bellas-artes, e sempre temos palavras lisongeiras e animadoras para aquelles que são modestos, que trabalham e fazem o que pódem. ${ }^{17}$

\section{Bibliografia}

ARGAN, Giulio Carlo. Arte e crítica de arte. Lisboa: Editorial Estampa, 1988.

BARATA, Mário. Artes plásticas de 1808 a 1889. In: Sérgio Buarque de Holanda. História geral da civilização brasileira - O Brasil monárquico. São Paulo: DIFEL, 1969, t.II, vol.3, p.410-425.

CAGNIN, Antonio Luis. Angelo Agostini: imagens do Brasil Império - caricaturas e quadrinhos. Haia, 1996.

DUQUE ESTRADA, Luiz Gonzaga. A Arte Brasileira. Mercado das Letras. Campinas, 1995.

FERREIRA, Félix. Belas Artes: Estudos e Apreciações. Publicação Digital, ArteData, 1998.

GUARILHA, Hugo. A questão artística de 1879: um episódio da crítica de arte do II Reinado. In: Anais do XXIII Colóquio do Comitê Brasileiro de História da Arte. Sonia Gomes Pereira, Roberto Conduru, org. Rio de Janeiro: CBHA/UERJ/UFRJ, 2004. p.195-202.

\footnotetext{
${ }^{16}$ Revista Illustrada, Rio de Janeiro, 1887, ano XII, n.459. p.6 e 7
}

${ }_{17}$ Revista Illustrada, Rio de Janeiro, 1883, ano VIII, n.363. p.3 e 6 